\title{
Elementos da abordagem temática no Ensino Médio: sinalizações para formação de professoras e de professores
}

\author{
Thematic approach in High School: \\ signposts for Teacher Education
}

\author{
Luciano Fernandes Silva ${ }^{1}$. https://orcid.org/0000-0003-2041-3809 \\ Swellen Sales Tavares ${ }^{2}$. https://orcid.org/0000-0002-3431-1187 \\ Giselle Watanabe ${ }^{3}$. https://orcid.org/0000-0002-3738-7160 \\ Karine Raquiel Halmenschlager ${ }^{4}$. https:/ / orcid.org/0000-0003-2747-3601 \\ Roseline Beatriz Strieder ${ }^{5}$. https://orcid.org/0000-0001-8965-8906 \\ Sandra Hunsche ${ }^{6}$. https://orcid.org/0000-0001-9766-5049
}

\begin{abstract}
Resumo: Neste trabalho identificam-se elementos que caracterizam a abordagem de temas inseridos na ação de professoras e professores que cursaram Licenciatura em Física e que participaram, ao longo do processo formativo, de discussões sobre Abordagem Temática. A investigação é de natureza qualitativa, sendo utilizados questionários com perguntas abertas e fechadas, assim como entrevistas semiestruturadas. Participaram de todas as etapas desta investigação dezoito sujeitos de oito instituições de Ensino Superior brasileiras. A análise dos dados foi realizada com base nos princípios da análise de conteúdo, a partir de duas categorias: natureza do tema e critérios de seleção das temáticas. Dentre os resultados, destaca-se que os e as docentes, predominantemente, têm desenvolvido temáticas contextuais selecionadas a partir do interesse e/ou do cotidiano dos(as) estudantes, indicando preocupação com a significação dos conceitos científicos escolares a partir do estabelecimento de relações entre aspectos da vivência da(o) aluna(o) e do conteúdo conceitual escolar.
\end{abstract}

Palavras-chave: Abordagem temática. Ensino de física. Formação de professores. Ensino médio.

Abstract: In this study, some features have been identified about the Thematic Approach that underlies teachers' actions. All the teachers who participated in this study were following the Bachelors' degree in Physics and have studied the Thematic Approach. This is a qualitative study, and eighteen teachers completed a semi-structured interview and some questionnaires. This group has participants who have studied in eight different Brazilian universities. Content Analysis was utilized in this research, and two categories were established: the theme's nature and theme selection criteria. The results show that most teachers emphasize contextual themes with a focus on the students' daily lives. This situation could indicate that teachers focus on the knowledge and skills needed for the application of scientific knowledge.

Keywords: Thematic approach. Physics teaching. Teacher education. Secondary school.

\footnotetext{
${ }^{1}$ Universidade Federal de Itajubá (UNIFEI), Instituto de Física e Química, Itajubá, MG, Brasil.

E-mail: lufesilva@unifei.edu.br

${ }^{2}$ Secretaria de Educação do Estado de Minas Gerais, Itajubá, MG, Brasil.

${ }^{3}$ Universidade Federal do ABC (UFABC), Centro de Ciências Humanas e Naturais, Santo André, SP, Brasil.

${ }^{4}$ Universidade Federal de Santa Catarina (UFSC), Departamento de Metodologia, Florianópolis, SC, Brasil.

${ }^{5}$ Universidade de Brasília (UnB), Instituto de Física, Brasília, DF, Brasil.

${ }^{6}$ Universidade Federal do Pampa (Unipampa), Caçapava do Sul, RS, Brasil.
} 


\section{Introdução}

Em resposta às demandas da sociedade contemporânea, passa a haver, no Ensino Médio (EM), uma preocupação com a formação para a cidadania e com a busca pela atribuição de significado ao conhecimento escolar (BRASIL, 2002). Nesse contexto, recomenda-se que os conteúdos escolares contemplem, para além dos conceitos científicos, a abordagem de temas (HALMENSCHLAGER; DELIZOICOV, 2017; WATANABE; KAWAMURA, 2017). Um dos desafios para implementação dessa abordagem volta-se à formação de professores(as), já que o êxito de propostas dessa natureza implica considerar que elas devem ser vivenciadas, compreendidas e incorporadas pelos educadores (SILVA; CARVALHO, 2009).

Diante disso, algumas iniciativas foram realizadas no contexto da formação inicial de professores(as) de Física em distintas instituições brasileiras de Ensino Superior, as quais estão descritas em Feistel et al. (2011), Gehlen et al. (2014), Hunsche (2010); Hunsche e Auler (2009, 2012); Silva e Carvalho (2009, 2012); Strieder, Hunsche e Watanabe-Caramello (2010); Strieder, Watanabe-Caramello e Gehlen (2010, 2012); Watanabe-Caramello, Strieder e Gehlen (2011, 2012). Essas iniciativas fundamentaram-se na perspectiva da Abordagem Temática proposta por Delizoicov, Angotti e Pernambuco (2007) em articulação com referenciais ligados à Educação Ciência-Tecnologia-Sociedade (CTS), à Educação Ambiental e aos pressupostos freireanos. De maneira geral, como apontam as referidas pesquisas, essas discussões contribuíram para uma formação mais crítica e autônoma dos(as) licenciandos(as), possibilitando novas compreensões acerca do currículo escolar e do papel do(a) professor(a) na construção desse currículo, assim como sobre o conhecimento escolar e os critérios de seleção desse conhecimento. Salienta-se que esses trabalhos foram realizados enquanto os(as) licenciandos(as) encontravam-se no último e/ou penúltimo semestre dos seus cursos. Dessa forma, envolveram a investigação de desafios e potencialidades encontrados ao longo do processo, considerando as compreensões e as ações dos sujeitos enquanto alunos(as) dos cursos de licenciatura em Física.

Como continuidade dessas pesquisas, investigamos ações e significados que esses sujeitos elaboram sobre trabalhos organizados a partir de temas, enquanto professores(as) da Educação Básica e/ou Superior. Diante disso, o problema de investigação refere-se a "Qual a natureza dos temas abordados pelos professores e professoras e que parâmetros utilizam para definir as temáticas tratadas em sala de aula?".

Investigamos, portanto, se e quais elementos foram incorporados nas ações e compreensões de professores e professoras recém-formados que participaram, durante sua formação inicial, do processo de elaboração e/ou desenvolvimento de propostas de ensino centradas em temas. Neste trabalho, voltamos a discussão para a natureza dos temas e os parâmetros empregados na seleção das temáticas pelos professores e professoras, pois a análise desses dois aspectos pode contribuir para identificar em que medida novos elementos foram inseridos aos programas escolares, se e como está ocorrendo a superação da abordagem conceitual a partir do trabalho pedagógico pautado em temas, permitindo analisar quais pressupostos relacionados à Abordagem Temática (DELIZOICOV; ANGOTTI; PERNAMBUCO; 2007) podem estar sendo incorporados pelos egressos. 


\section{Fundamentação Teórica}

A área de pesquisa em Educação em Ciências tem elaborado propostas curriculares que organizam o conteúdo programático por meio de temas, as quais estão baseadas em distintos pressupostos teórico-metodológicos (HALMENSCHLAGER; DELIZOICOV, 2017). Dentre essas, neste trabalho, destacamos os temas fundamentados em pressupostos da Educação Ciência-Tecnologia-Sociedade (CTS), da Educação Ambiental e de Paulo Freire.

De acordo com Halmenschlager e Delizoicov (2017), a inserção dessas perspectivas temáticas nos programas escolares tem acontecido de duas formas: (i) pontual, configurando estratégia metodológica em que as práticas são realizadas em um determinado número de aulas envolvendo blocos de conteúdos; ou (ii) de forma ampliada, em que o foco é a reestruturação do currículo a partir da abordagem de temas. Além disso, os autores supracitados destacam que, entre os aspectos que contribuem para caracterizar as propostas, estão: (i) a natureza dos temas, que pode ser de natureza conceitual, quando contempla "[...] principalmente, aspectos relacionados, exclusivamente, com a conceituação científica, e eventual uso dela, a título de exemplificação, em situações da vivência do aluno, sendo a temática expressa a partir de determinado conceito ou de articulações entre diferentes conceitos" (HALMENSCHLAGER, DELIZOICOV, 2017, p. 3); ou uma natureza contextual, quando os temas estão "[...] relacionados, dentre outros, com fenômenos naturais ou tecnológicos, situações representativas de determinado contexto geopolítico, situações problemas e contradições (FREIRE, 2005), questões ambientais" (HALMENSCHLAGER, DELIZOICOV, 2017, p. 3); e (ii) a função dos conceitos científicos, que possibilita analisar as relações estabelecidas entre a temática e a conceituação científica e se relaciona intrinsecamente com os critérios de seleção das temáticas e com a relação de dependência entre temas e conceitos científicos, pois tanto os conceitos podem estar subordinados ao tema quanto podem orientar a escolha da temática.

Particularmente, no que diz respeito aos temas fundamentados em pressupostos da Educação CTS, apesar de reconhecermos sua polissemia, destacamos, neste trabalho, a perspectiva dos compromissos sociais (STRIEDER; KAWAMURA, 2017). Nesse sentido, devem ser abordados temas que se configuram como problemas que afligem a sociedade contemporânea, marcados por ciência e tecnologia e, também, por desequilíbrios sociais, políticos, éticos, culturais e ambientais. Essa perspectiva apresenta elementos comuns aos pressupostos freireanos, no sentido em que visa a abordar a realidade de forma a identificar caminhos para sua transformação e, associado a isso, fundamenta-se em pressupostos da Abordagem Temática (DELIZOICOV; ANGOTTI; PERNAMBUCO, 2007).

Os temas fundamentados em pressupostos da Educação Ambiental também se caracterizam pela polissemia quanto aos pressupostos teóricos e metodológicos. Todavia, de forma geral, as produções da área da Educação em Ciências que se pautam por temas ambientais se caracterizam por: (i) uma formulação e organização dos conteúdos pouco explicitados, caracterizando-se por programas que apresentam tópicos de rotina; (ii) estratégias e uma lógica de atividades que não apresentam um fio condutor claro, de forma a privilegiar propostas pontuais que apresentam um desenvolvimento metodológico parcial, atomizado e aditivo; e (iii) uma atuação educativa na qual não fica claro para os participantes o protagonismo do(a) aluno(a), reduzindo-se a uma atividade mais manipulativa do que reflexiva (RODRIGUEZ-MARÍN; GARCÍA, 2009). Por outro lado, em pesquisas mais recentes, é possível identificar certa 
preocupação com a complexidade que esses temas trazem, de modo que ganham destaques trabalhos que apresentam uma perspectiva (i) com aproximações pontuais à complexidade; (ii) com potencial - em transição - à complexidade; e (iii) com alto potencial - consolidada - à complexidade (WATANABE, RODRÍGUEZ-MARÍN; 2018). Em (iii), trata-se de se considerar uma complexidade explícita voltada à perspectiva integradora, na qual o conhecimento escolar pauta-se na integração transformadora de diversas formas de conhecimentos, existindo uma continuidade entre os conhecimentos científico e cotidiano. Foi essa última perspectiva que orientou os trabalhos desenvolvidos na presente pesquisa.

Por fim, no âmbito da Abordagem Temática Freireana, na perspectiva defendida por Delizoicov, Angotti e Pernambuco (2007) e neste trabalho, a inserção das temáticas nos programas escolares configura-se como um processo de reconstrução curricular, a partir de Temas Geradores (FREIRE, 2005). O Tema Gerador representa um problema / contradição vivenciada pela comunidade escolar, que será identificado por meio da investigação da realidade. Delizoicov Angotti e Pernambuco (2007) sugerem, com base em Freire (2005), a realização da dinâmica da Investigação Temática ${ }^{7}$. Assim, essa perspectiva tem, entre seus pressupostos: (i) que a temática precisa representar uma contradição que necessita enfrentamento; (ii) a investigação da realidade como critério para a seleção dos temas; (iii) o aluno como sujeito do conhecimento; (iv) a dialogicidade como princípio educativo, desde o momento da elaboração do programa escolar até o seu desenvolvimento em sala de aula.

Esses pressupostos fundamentaram esta investigação, desde as discussões que ocorreram durante a formação inicial dos licenciados até a análise dos dados, como será explicitado a seguir.

\section{Procedimentos Metodológicos}

O presente estudo é de natureza qualitativa e se caracteriza por ser uma pesquisa do tipo empírica. Participaram, como sujeitos da pesquisa, egressos de cursos de licenciatura em Física de diferentes instituições brasileiras que tiveram, durante a graduação (entre 2009 e 2014), contato com discussões centradas na Abordagem Temática em componentes curriculares de seus cursos, sendo essas: Universidade Federal de Santa Maria (UFSM), Universidade Católica de Brasília (UCB), Universidade Federal do Mato Grosso do Sul (UFMS), Instituto Federal de São Paulo (IFSP) e Universidade Federal de Itajubá (UNIFEI). Apesar de desenvolvidas de forma diferenciada em cada instituição devido às peculiaridades de cada curso, as discussões

\footnotetext{
${ }^{7}$ A Investigação Temática pode ser entendida como a dinâmica pela qual o programa escolar é estruturado. É desenvolvida em cinco etapas, conforme sistematizado por Delizoicov, Angotti, Pernambuco (2007): (1) reconhecimento preliminar, que consiste em reconhecer o contexto sócio-histórico-econômico-cultural em que vive o aluno; (2) escolha de contradições vividas pelo aluno que expressam de forma sintetizada o seu modo de pensar e de ver/interagir com o mundo, bem como a escolha de codificações; (3) obtenção dos Temas Geradores a partir da realização de diálogos descodificadores; (4) redução temática: trabalho em equipe interdisciplinar, com o objetivo de elaborar o programa curricular e identificar quais conhecimentos são necessários para o entendimento dos temas; e, (5) desenvolvimento do programa em sala de aula.
} 
realizadas com os licenciandos tiveram como objetivo orientar o desenvolvimento de trabalho educativo a partir de temas.

Como instrumentos de coleta de informações foram utilizados questionários on-line com questões abertas e fechadas e entrevistas semiestruturadas, realizados em 2015 e 2016, respectivamente. O questionário on-line foi criado a partir da plataforma google docs e envolveu dois blocos de questões. O primeiro bloco foi formado com perguntas voltadas para a caracterização do sujeito de pesquisa, identificando dados relativos à sua formação (instituição e ano de conclusão do curso) e dados gerais referentes à atuação profissional (se já lecionou, se atuou na rede pública e/ou privada, disciplinas ministradas e se desenvolveu algum trabalho com viés temático). O segundo bloco de questões foi respondido por aqueles que afirmaram ter desenvolvido, em algum momento de sua atuação profissional em escolas públicas e/ou privadas, propostas elaboradas a partir de temas. Essas questões tiveram como objetivo buscar elementos para a caracterização do trabalho temático desenvolvido em sala de aula. Por isso, perguntou-se quais temas haviam sido abordados, por que esses temas foram escolhidos, que atividades foram desenvolvidas para o estudo do tema e em que contexto elas foram desenvolvidas.

A entrevista semiestruturada foi elaborada com a intenção de aprofundar e/ou confirmar aspectos relacionados à elaboração e implementação das propostas temáticas, destacados pelos(as) professores(as) que responderam a segunda parte do questionário. A entrevista foi composta por perguntas a serem respondidas pelos sujeitos que afirmaram, nos questionários, ter desenvolvido propostas temáticas.

$\mathrm{Na}$ primeira etapa do processo de coleta de informações, localizamos todos os 42 egressos que participaram das atividades desenvolvidas no período de 2009 a 2014 nas instituições já mencionadas anteriormente, os quais foram convidados a responder ao questionário enviado por e-mail. Todos os egressos contatados responderam ao questionário. Desses, 23 eram docentes em escolas da Educação Básica e 18 implementaram propostas temáticas em suas aulas. Embora os 18 tenham sido convidados para a entrevista, somente 12 aceitaram participar, os quais foram entrevistados on-line por um dos pesquisadores deste projeto. Essas entrevistas duraram entre 45 e 60 minutos e foram transcritas na íntegra.

Neste artigo, apresentaremos a análise proveniente dos questionários dos 18 professores que implementaram propostas temáticas em suas práticas pedagógicas e também das entrevistas realizadas com os 12 professores provenientes desse grupo que aceitaram participar dela.

As informações obtidas foram analisadas mediante a Análise de Conteúdo (BARDIN, 1991) em torno de três polos cronológicos: a pré-análise, a exploração do material, e o tratamento dos resultados, que envolve a inferência e a interpretação dos dados. Dentre as diferentes técnicas de Análise de Conteúdo utilizamos aquela reconhecida por análise temática ou categorial, que permite classificar elementos de significação comuns, referenciando nos critérios de classificação do que se procura ou do que se pretende encontrar.

Realizar a análise temática consiste em identificar os núcleos de sentido que compõem a mensagem (conteúdo). Para isso, procuramos identificar as unidades de registro que estavam diretamente relacionadas com o tema da investigação. Importante ressaltar que, para Bardin (1991), o tema se apresenta como uma afirmação sobre um assunto, ou ainda uma frase ou uma frase composta, ou ainda uma frase condensada que possa vir a influenciar um vasto conjunto de formações singulares. A identificação dos temas ocorre na fase da codificação da mensagem. Em seguida, na fase da categorização, ocorre a divisão dos temas em categorias segundo as 
suas características comuns. Ainda, segundo Bardin (1991), pode-se trabalhar com categorias a priori, sugeridas pelo referencial teórico e com categorias a posteriori, elaboradas após a análise do material. Nesta investigação, trabalhou-se com as categorias dadas a priori "natureza dos temas" e "critérios de seleção dos temas".

\section{Resultados: a natureza e a seleção de temas}

Os resultados são apresentados a partir das categorias: natureza dos temas e critérios de seleção dos temas. Nessa apresentação, os(as) professores(as) estão identificados(as) como P1, P2, P3, ..., P18, resguardando-se suas identidades.

\section{Natureza do Tema}

Dezoito docentes, dos vinte e três que afirmaram atuar na Educação Básica, salientam ter trabalhado com temas em suas respectivas escolas. Para a análise da natureza dos temas abordados pelos(as) professores(as), considerou-se o que Halmenschlager e Delizoicov (2017) definem como natureza conceitual e natureza contextual. Ressalta-se que a análise levou em consideração, além do próprio "título/nome" do tema, as demais respostas dadas pelos sujeitos que participaram desta investigação, tanto no questionário on-line quanto na entrevista semiestruturada, em especial, as informações que disponibilizaram sobre as atividades realizadas a partir do tema e o papel do tema no processo de ensino e aprendizagem. O Quadro 1 apresenta uma sistematização da natureza dos temas desenvolvidos em sala de aula pelos professores.

A análise indica que os temas abarcam, prioritariamente, a natureza contextual, o que sugere que a maioria dos(as) docentes demonstra uma preocupação em estabelecer alguma aproximação entre o conhecimento científico escolar e aspectos da vivência dos(as) estudantes.

Quadro 1 - Natureza dos temas desenvolvidos em sala de aula

\begin{tabular}{|c|c|c|}
\hline Egresso & Tema & $\begin{array}{r}\text { Natureza } \\
\text { do Tema }\end{array}$ \\
\hline P1 & (1) Espelhos Esféricos; (2) Física sobre duas Rodas; (3) Buracos Negros & Conceitual \\
\hline $\mathrm{P} 2$ & $\begin{array}{l}\text { (1) Poluição Sonora; (2) Escassez de Água; (3) Tecnologia e o } \\
\text { Desenvolvimento Social; (4) Catástrofes Naturais }\end{array}$ & Contextual \\
\hline P3 & $\begin{array}{l}\text { (1) Consequências do Lixo Tecnológico; (2) Política e Cidadania; (3) } \\
\text { Tecnologia e Sociedade: para onde vamos? }\end{array}$ & Contextual \\
\hline P4 & (1) Raio Laser; (2) Lixo Eletrônico & Conceitual \\
\hline P5 & (1) Componentes Eletrônicos & Conceitual \\
\hline P6 & $\begin{array}{l}\text { (1) Revolução Industrial: evolução das máquinas a vapor, capitalismo e } \\
\text { regionalização }\end{array}$ & Contextual \\
\hline P7 & (1) Mudanças Climáticas; (2) Geração de Energia Elétrica & Contextual \\
\hline P8 & (1) O Desenvolvimento Tecnológico na África; (2) Fontes de Energia & Contextual \\
\hline
\end{tabular}


Quadro 1 - continuação

\begin{tabular}{|c|c|c|}
\hline Egresso & Tema & $\begin{array}{l}\text { Natureza } \\
\text { do Tema }\end{array}$ \\
\hline P9 & (1) Sistema Nervoso e os Cinco Sentidos & Conceitual \\
\hline P10 & $\begin{array}{l}\text { (1) Física Moderna; (2) Física nas Revoluções Industriais; (3) } \\
\text { Aerodinâmica; (4) Exploração Espacial; (5) Astrofísica }\end{array}$ & Contextual \\
\hline P11 & $\begin{array}{l}\text { (1) Deformação de Carros Modernos em Colisões; (2) Uso de Radiação } \\
\text { no Tratamento Médico; (3) Espectroscopia na Busca por Planetas com } \\
\text { Clima Parecido com o da Terra }\end{array}$ & Contextual \\
\hline P12 & $\begin{array}{l}\text { (1) Fotografia; (2) Produção de Energia Elétrica em Larga Escala; (3) } \\
\text { Poluição Sonora; (4) Arquitetura; (5) Meio Ambiente; (6) Copa do Mundo }\end{array}$ & Conceitual \\
\hline P13 & $\begin{array}{l}\text { (1) Impacto Ambiental das Usinas de Geração de Energia Elétrica; (2) } \\
\text { Lixo Eletrônico; (3) Telecomunicações }\end{array}$ & Contextual \\
\hline P14 & $\begin{array}{l}\text { (1) A Física na Cultura Afro-Brasileira; (2) A Atuação dos } \\
\text { Afrodescendentes na Evolução da Ciência; (3) As Enchentes em Itacaré; } \\
\text { (4) As Consequências do Salitro nas Estruturas das Residências; (5) A } \\
\text { Diminuição do Nível do Mar na Praia da Orla }\end{array}$ & Contextual \\
\hline P15 & (1) Energias Renováveis & Contextual \\
\hline P16 & (1) LHC; (2) Raios & Conceitual \\
\hline P17 & (1) Tecnologia e Desenvolvimento Científico & Contextual \\
\hline P18 & $\begin{array}{l}\text { (1) Astronomia; (2) Saúde; (3) Sustentabilidade; (4) Ecologia; (5) } \\
\text { Tecnologia }\end{array}$ & Contextual \\
\hline
\end{tabular}

Fonte: elaborado pelos autores.

Em alguns casos, essa aproximação ocorre por meio de temas relacionados a fenômenos naturais e/ou tecnológicos e situações representativas de determinado contexto, a exemplo de P11, que, ao trabalhar com o tema Deformação de carros modernos em colisões, estabeleceu relações entre aspectos pautados em acidentes de carros e conceitos físicos. Em outros casos, a exemplo do tema Física nas revoluções industriais, desenvolvido por P10, a ênfase esteve no contexto histórico-social, relacionando-o com a Física. Para além dessa perspectiva de aproximar os conhecimentos científicos a distintos contextos, em alguns trabalhos, a conceituação científica abordada configurou instrumento para os(as) estudantes compreenderem e intervirem em sua realidade, em sintonia com o que defende a Abordagem Temática. Isso comparece, por exemplo, no tema desenvolvido por P7, que englobou as diferentes formas de energia elétrica, conceitos físicos (como potência, corrente elétrica e tensão) e também aspectos sociais, políticos e econômicos. Além disso, a partir do estudo realizado em sala de aula, buscou determinar ações que contribuíssem para a diminuição do consumo de energia elétrica na escola.

De forma semelhante, os temas As enchentes em Itacaré, As consequências do salitro nas estruturas das residências e $A$ diminuição do nivel do mar na praia da Orla, desenvolvidos por P14, com caráter socioambiental, possuem relação com problemáticas locais/ regionais presentes no contexto dos(as) estudantes. Segundo P14, ao responder o questionário: 
No caso das enchentes, eram discutidos várias questões pertinentes, como as doenças, a vazão da água, possíveis soluções para impedir a sua ocorrência anual com maquetes; No caso do salitro, haviam discussões sobre onde estavam as incidências deste nos locais públicos, depois eram estudados como ocorre a reação química principalmente nos metais; No caso da diminuição do nível do mar, era pedido que os alunos descrevessem as causas, depois adentrava sobre o fenômeno das marés cheia e baixa, a influência das construções do homem no nível do mar, as brisas marítimas e terrestres e o derretimento das calotas polares e o efeito estufa. [P14].

$\mathrm{O}$ (a) docente - na entrevista - argumentou ainda que:

A gente se preocupava também com as questões sociais. Por exemplo, no projeto de captação de aquecedor solar, para esquentar a água a gente utilizou de garrafa pet. Foi uma atividade mais sociocultural do que uma atividade da Física. Na bora os alunos tiveram que mostrar o projeto deles, e explicar como funcionava, tinha que falar sobre isso também. Então também foi uma atividade voltada para essa parte. Na questão da bistória da ciência, ele não mostrava apenas a visão do cientista, ele mostrava apenas a quebra da visão do cientista como um ser que vivia sozinho, que não tinha erros, mostrar que ele errou muito ao chegar naquele resultado, que eles sofreram muito com questões proibidas da época, como Galileu e a história da igreja, por causa das suas ideias. Então, mostrava isso também. [P14].

A partir desses dados, sinalizam-se que alguns assuntos estão relacionados com temáticas que têm o potencial de abordar contradições e problemáticas do meio ambiente. Tais características foram contempladas e reforçadas nas entrevistas de P7, P14 e P15 ao expressarem a preocupação em relacionar questões energéticas com impactos socioambientais. Ressalta-se, também, o fato de que estas propostas envolveram pesquisas realizadas pelos(as) estudantes (algumas teóricas, outras de campo), indicando uma preocupação com seu protagonismo, aspecto central nas discussões sobre a abordagem de temas ambientais e sociais. Esse parece ser um caminho interessante para professores(as) de Física desenvolverem trabalhos de Educação Ambiental, sobretudo considerando que, normalmente, há grande dificuldade de professores desta disciplina se identificarem com temáticas ambientais (SILVA, CARVALHO, 2009).

Outros professores, no entanto, abordaram temáticas de natureza conceitual, em que os desdobramentos de sua abordagem têm relação estreita com a estrutura conceitual que tradicionalmente orienta a organização dos programas escolares, a exemplo de P16, que afirma no questionário: “[...] precisava planejar as aulas de forma que inserisse força elétrica, carga elétrica, partículas elementares e átomos. Para isso, houve uma apresentação expositiva e oral por meio de Power Point e vídeos com simulações do funcionamento interno do LHC' [P16].

P5, de forma semelhante a P16, ao abordar o tema Componentes eletrônicos, tinha como principal finalidade discutir os conceitos de tensão, corrente elétrica e associação de resistores, sem priorizar elementos voltados às questões sociais. Também P12, ao discorrer, na entrevista, sobre os temas que abordou em sala de aula, destaca, predominantemente, aspectos conceituais: 
Eu abordei bastante a parte de ótica. Mas não foi só esse que eu trabalbei em um projeto. Eu também trabalhei com mecânica a partir do tema copa do mundo. Outro tema que a gente abordou foi a arquitetura, no qual eu trabalhei com força, lei de Newton e traşão dentro da arquitetura. A gente trabalhou também com o tema de meio ambiente, onde eu abordei um pouquinho as coisas de efeito estufa. Então, tem bastante coisa que eu consegui trabalhar. [P12].

As aulas de P12 foram pautadas em projetos que têm a finalidade de trazer o cotidiano do(a) aluno(a) para exemplificar o conceito físico. P12 afirmou, no questionário, possuir certa dificuldade em desenvolver em sala de aula características sociais, econômicas e políticas do tema. Para ele: "Não tem como. Sabe o fato é basicamente o superficial mesmo. É o básico da Física". (P12).

Essas propostas temáticas (P5, P12 e P16) configuram uma abordagem mais conceitual. Salienta-se que, quando trabalhada sob essa perspectiva, a temática tem como principal papel ilustrar e exemplificar a aplicação de conceitos e operar como elemento motivacional do processo de ensino e aprendizagem.

Em síntese, os resultados indicam que as temáticas abordadas pelas professoras e professores em sala de aula possuem distintas naturezas, envolvendo, em alguns casos, prioritariamente aspectos conceituais, e, em outros casos, aspectos sociais, ambientais e/ou políticos. Contudo, embora a maior parte dos(as) docentes considere importante relacionar os conceitos físicos escolares com o cotidiano, aproximando-se do que defende a Abordagem Temática, poucos(as) fizeram referência às contradições sociais a serem superadas, cerne da proposta.

Algumas temáticas mencionadas pelos(as) professores(as) envolvem contradições, a exemplo de Lixo tecnológico, política e cidadania e Tecnologia e sociedade: para onde vamos?, abordadas por P3 e de Mudanças climáticas e Geração de energia elétrica, desenvolvidas por P7. Porém, em seus relatos, os(as) professores(as) não mencionam contradições. Isso pode estar associado tanto às suas compreensões sobre o propósito do trabalho com temas, quanto aos seus entendimentos sobre as temáticas em questão.

A localização de contradições envolve estudos aprofundados da temática a ser abordada, o que exige disponibilidade de tempo e dedicação por parte dos(as) professores(as). Também, é importante ressaltar que esse estudo não basta, pois apenas retrata a visão dos(as) professores(as), e não dos indivíduos. Assim, além disso, é necessário compreender o que os sujeitos pensam a respeito do tema em questão e da sua situação existencial e, para isso, é preciso ouvi-los.

As contradições, na perspectiva freireana, estão associadas às posições de manutenção e mudança da estrutura dominante, opressora, e se constituem em situações limites, entendidas como intransponíveis e paralisantes pelos sujeitos em processo de libertação. Sendo assim, qualquer ato educativo, na perspectiva da Abordagem Temática, precisa envolver o diálogo em torno da realidade com a qual os sujeitos se encontram. A ausência desse estudo e de reflexões em torno das compreensões pessoais, dos alunos e das alunas e da sociedade sobre o tema, dificulta a localização de contradições. Como colocado por Silva (2007, p. 11), "se não houver escuta, não haverá diálogo e nossa ação se dará sobre ou para e não com ela. Consequentemente não haverá libertação, nem transformação da realidade".

Localizar e discutir contradições sociais presentes nos temas, com a intenção de superá-las não é tarefa simples, exige a superação da contradição educador-educandos. Lembramos que, de acordo com Freire (2005, p. 96) "[...] os homens se educam em comunhão, mediatizados 
pelo mundo. Mediatizados pelos objetos cognoscíveis que, na prática "bancária”, são possuídos pelo educador que os descreve ou os deposita nos educandos passivos.”. Portanto, associado à natureza dos temas trabalhados pelos professores, destacamos o desafio de superar a perspectiva bancária de educação.

\section{Critérios de Seleção dos Temas}

De acordo com os dados obtidos a partir dos questionários e das entrevistas, temos que as propostas foram pensadas e organizadas pelos(as) professores(as) para serem trabalhadas, em sua maioria, no contexto do Ensino Médio regular ou em situações educativas que pressupõem o trabalho com conhecimentos equivalentes ao desse nível de ensino, no componente curricular de Física.

P9, por exemplo, trabalhou a partir de um tema quando esteve em um curso pré-vestibular. Segundo o(a) docente, não houve um critério específico para a escolha do tema, mas a finalidade era trabalhar com o máximo de conceitos de Física que fosse possível. $O(A)$ docente relata que a proposta era uma forma de auxiliar os(as) discentes a estudarem o máximo de conceitos científicos escolares possíveis em um menor período de tempo, contribuindo para melhorar o desempenho no exame de inserção no Ensino Superior. Em suas palavras, a ideia do tema:

\section{[...] surgiu e foi bem espontânea. Eu estava discutindo com um amigo e a gente começou a falar sobre isso, sobre a dificuldade de se trabalhar com todos os conteńdos, e ai a gente foi elencando coisa do dia a dia da gente. E vimos que eu conseguiria trabalhar todos os temas que eu precisava dentro do sistema nervoso, porque tinha toda a parte elétrica, toda parte mecânica, toda parte de térmica e então tinha tudo. Só que eu não consegui trabalhar relatividade geral e quântica. [P9].}

Por outro lado, outros fatores para orientar e justificar a escolha do tema foram destacados pelos(as) participantes. Alguns descrevem várias justificativas, ora se apoiando na experiência que têm com o tema ou ainda indicando que a escolha foi orientada a partir das demandas dos(as) alunos(as) ou das demandas da escola na qual trabalham.

Uma das justificativas mais citadas (presente nas falas de P2, P9, P11 e P18) argumenta que o tema deve estar próximo do cotidiano dos alunos. As falas de P2 e de P9, apresentadas a seguir, exemplificam isso:

Por fazer parte do cotidiano dos estudantes, por facilitar a aquisição do conbecimento de física e para fomentar a elaboração de ideias para a solução dos problemas propostos. [P2].

Por ser algo extremamente próximo aos estudantes e de criar, através do tema, uma linha de raciocinio bastante interessante para se tratar os conteídos necessários. [P9].

Um grupo de professores(as) justificou a escolha do tema tendo por base o interesse dos(as) estudantes, como é caso de P1, P3, P7, P10, P11, P14, P17 e P18. Esse agrupamento se aproxima daquele das vivências cotidianas $\operatorname{dos}(\mathrm{as})$ alunos(as), porém se distancia deste pelo fato de que os interesses da turma podem não estar vinculados ao cotidiano. Por exemplo, segundo o questionário respondido por P1, os temas: "Espelhos Esféricos, A Física sobre duas rodas e Buracos 
Negros [...] fazem com que os alunos consigam identificar os conceitos trabalhados em sala de aula e despertam o interesse pelas curiosidades da Física” [P10].

Especificamente no caso de P7, que apresenta várias justificativas para o trabalho com a Abordagem Temática, há também a construção de uma justificativa na qual afirma que escolheu o tema Geração de energia elétrica porque este era de interesse imediato dos(as) estudantes: “[...] mediante as indagações que os próprios alunos apresentavam sobre o assunto" (P7). Por outro lado, P7 cita a base curricular oficial do estado de Minas Gerais como sendo uma justificativa para a escolha do tema, como explicita o fala a seguir: "Trabalho com o tema porque é sugerido pelo CBC (conteúdo básico comum) que é utilizado na escola onde trabalho".

A partir das considerações de $\mathrm{P} 7$, nota-se que há uma tentativa em conciliar vários critérios para escolher um tema. No caso de P7, há uma busca por um tema diferente, que seja do cotidiano dos(as) alunos(as), com algo que seja do contexto curricular oficial. Além dessa, outros(as) professores(as) justificam a escolha dos temas a partir das demandas da escola, como no caso dos P8, P14, P12 e P16. A seguir, dois exemplos de respostas apresentados ao questionário on-line:

Trabalbo em uma escola em que utilizamos temas como foco nos semestres. Dessa forma a escola quem escolheu os temas a serem tratados. No entanto, antes de trabalhar nesta escola tive experiência em abordar assuntos temáticos em algumas aulas de física. A escolha pelos temas se dava na maioria das vezes por conta do conteído a ser abordado. Poucas vezes parti primeiramente do tema. [P12].

Os temas foram escolbidos conforme os conteúdos do Referencial Curricular do estado de Mato Grosso do Sul, pois as aulas deveriam ser obrigatoriamente planejadas conforme os conteúdos contidos neste. [P16].

Tal como P7, P16 cita o currículo oficial do seu Estado como uma justificativa para a escolha do tema. Enfim, os dados indicam que algumas orientações curriculares oficiais incentivam os(as) professores(as) a trabalhar com Abordagem Temática.

A familiaridade do(a) docente com o tema também foi critério de seleção para alguns, a exemplo de P4 e P7. O fato de ter feito bons trabalhos sobre o assunto da graduação foi o que motivou P4.

P7, por sua vez, escreveu que também considerou, como critério para a escolha do tema, o fato de ter estudado as ideias desenvolvidas na escola a partir de em um mestrado realizado no campo da Educação em Ciências. Segundo esse(a) professor(a), em relato realizado ao longo da entrevista, esse foi o maior estímulo que teve para realizar trabalhos dessa natureza na escola. Segundo P7,

O que me motivou a trabalhar é que eu já tinha muita facilidade de trabalhar com esse tema, que foi um tema que eu estudei durante a minha graduação e estudei durante o mestrado. Como eu estava trabalhando no $2^{\circ}$ ano do Ensino Médio, nós estávamos iniciando os estudos sobre temperatura, termodinâmica, a parte de dilatação, a parte inicial do $2^{\circ}$ ano do Ensino Médio, e eu fiquei pensando em algum tema que eu poderia utilizar para trabalbar com este conceito [...]. Como eu já tinha um conbecimento 
bem aprofundado sobre o tema, tinha facilidade maior de trabalhar com este tema, do conbecimento que possuía sobre o assunto e por estar trabalhando com esses conceitos que envolvem, de maneira direta, questões relacionadas com temperatura, dilatação, que podem ser trabalhados dentro das mudanças climáticas, por isso en optei pelo trabalho com este tema. [P7].

P5 relatou, na entrevista, que, antes de dar aula de Física, era professor(a) no curso técnico, por isso escolheu abordar o tema que trata do funcionamento dos componentes eletrônicos. P10 também deixa explícito o seu gosto pessoal pela Astronomia, fato que o motivou a trabalhar com temas em suas aulas.

Há quem considerou as aproximações com a sociedade como sendo o fator decisivo para a escolha do tema, destacando sua importância histórica e/ou atual, como é o caso de P6 e P13. Segundo eles,

Porque foi um marco histórico, geográfico e tecnológico. [P6].

Por serem temas que estão bastante relacionados com a forma com o que o indivíduo interage com o mundo e a sociedade, seja no período escolar, seja ao término de seus estudos. [P13].

P3 definiu o tema por entender que ele desperta o senso crítico dos alunos com relação aos aspectos sociais da Ciência e da Tecnologia, como está explicitado na resposta a seguir retirada do questionário on line:

Para despertar a curiosidade e estimular o senso crítico do aluno, fazendo com que ele entenda que os avanços tecnológicos, não têm apenas beneficios, mas também vários maleficios sociais e ambientais. Também trabalhar o "lado cidadão" mostrando qual a função da política para a sociedade e quão importante é saber exercer a cidadania e ver que a educação é a fonte primária para esse despertar, contextualizando a disciplina dentro dessas problematizações. [P3].

Em respostas como a de P3, fica explícita a perspectiva política do processo educativo, sobretudo tendo em conta que a(o) docente entende que o processo educativo objetiva a formação de um cidadão crítico com relação aos avanços da Tecnologia.

P14, por sua vez, trabalhou com diversos temas de viés social, como: Enchentes em Itacaré, As consequências do salitro nas estruturas das residências e $A$ diminuição do nivel do mar na praia da Orla. Esses foram justificados como sendo uma escolha pessoal, tendo em vista os problemas sociais e ambientais da região onde a escola se situa. Nesse sentido, esses temas claramente abordaram a realidade local dos(as) discentes. Por meio das análises, é possível destacar que a proposta de P14, As enchentes em Itacaré, é a que mais se aproxima do Tema Gerador (FREIRE, 2005).

Também chamou nossa atenção a justificativa apresentada por P13 na entrevista, que indica uma preocupação com o desenvolvimento sustentável, sendo isso o que o incentivou a construir trabalhos educativos organizados a partir de temas: 
Eu sempre fui uma pessoa que acredita no desenvolvimento sustentável. E, cada vez mais, eu vejo uma degradação maior do meio ambiente e a despreocupação com as matérias primas. Então, a parte das usinas elétricas, a parte ambiental, o lixo eletrônico, é voltado nesse ponto, de você tentar não só um desenvolvimento sustentável mais moderar esse consumismo, pois muita gente fica endividada sem motivo. A parte de telecomunicações é uma parte da tecnologia que me fascina. Comunicação sem fio, internet, computadores... tudo isso foi uma coisa que me chamou muito atenção. Então, por isso esse foi outro tema utilizado. Além disso, também tem o fato dos alunos utilizarem muito do celular. Por que eu tenho que brigar com o celular na sala de aula se eu posso trazer o celularpara o meu lado? Ele me ajudar? Então por um lado foi uma questão pessoal minha, mas por outro foi ver que todos reclamam do celular, mas ninguém utiliza ele ao seu favor. [P13].

Percebe-se, portanto, em sintonia com outros estudos (HALMENSCHLAGER; DELIZOICOV, 2017), que distintos parâmetros podem ser adotados para justificar a escolha das temáticas, bem como há diferentes compreensões acerca do papel do tema e o processo de organização das atividades educativas, podendo ser tanto ilustrativo do conteúdo em estudo quanto eixo estruturador da ação docente. Ainda assim, alguns fatores parecem ser mais decisivos para a tomada de decisão de trabalhar com temas e, entre esses, estão: familiaridade do(a) professor(a) com o tema; demanda vinda da escola e/ou do sistema educativo; e a possibilidade de realizar um trabalho educativo mais próximo da realidade dos(as) estudantes.

Esses resultados podem ainda ser discutidos a partir do estudo realizado por Sund (2016). Em uma investigação realizada com professores e professoras da Educação Básica da Suécia, Sund (2016) destaca a existência de basicamente três grandes tradições (padrões) ligadas ao ideário docente do processo de alfabetização científica. Uma delas é denominada de Science disciplinary tradition e se identifica com a perspectiva de ensino voltada para os conceitos disciplinares e com objetivos mais próximos de oferecer aos estudantes a oportunidade de uma formação que os leve a ser encaminhados para uma futura profissão ligada às Ciências e à Tecnologia. Outra tradição, denominada Scientific informal application tradition, está, de modo geral, relacionada com a perspectiva de que os(as) estudantes deveriam aprender conceitos científicos para associá-los em contextos do dia-a-dia. Aqui, é importante considerar os interesses e as preferências dos(as) estudantes para motivá-los a aprender. A terceira tradição é denominada Scientifically informed societal tradition e se volta para a perspectiva de que o conhecimento científico deve possibilitar a resolução de problemas próximos da comunidade e o melhoramento de suas vidas. Para o autor, essa perspectiva é a que mais se aproxima daquela dos(as) professores(as) que trabalham com temas ambientais em aulas de Ciências a partir de uma tradição crítica do processo educativo.

Nessa perspectiva, os(as) professores(as) que se voltam mais para a perspectiva de trabalhar com temas contextuais e próximos da realidade da comunidade escolar, com a perspectiva da participação ativa dos(as) estudantes em discussões sobre problemas locais, parecem estar mais próximos do que Sund (2016) defende ser a tradição Scientifically informed societal tradition. Há ainda outros trabalhos que foram identificados pela categoria de temas contextuais que se aproxima mais da Scientific informal application tradition, ou seja, os temas são contextuais, porém a ideia básica, muitas vezes, é de uma aplicação dos conceitos em situações do dia-a-dia dos(as) alunos(as). Por sua vez, a perspectiva do trabalho com temas conceituais parece mais próxima da Science disciplinary tradition. 
Nessa linha, destacamos a importância de problematizar, na formação inicial, distintos propósitos atribuídos à educação científica, as controvérsias e contradições em torno dessa discussão e as compreensões dos(as) professores(as) sobre essa questão.

\section{Considerações Finais}

Os resultados desta investigação indicam que parte significativa dos docentes participantes de atividades formativas apoiadas em pressupostos da Abordagem Temática em seus cursos de graduação incorporaram a discussão em algum momento das suas atuações na Educação Básica. Esse fato pode ser um indicativo de que esse ideário educacional está sendo - aos poucos - incorporado pelos(as) professores(as).

Destacamos também que há uma preocupação em contemplar os conceitos que estão presentes no currículo básico comum e em orientar o trabalho a partir deles. Ou seja, nenhum(a) docente escolheu a temática sem deixar de relacioná-la com o conteúdo específico de Física presente na Educação Básica. Esse fato reforça a percepção de que a estrutura curricular escolar é o fator mais relevante na tomada de decisão que os(as) professores(as) principiantes realizam em relação ao que trabalhar na escola. Por outro lado, mostra a preocupação dos(as) docentes em trazer para as suas aulas o embasamento científico para, por exemplo, tratar das questões socioambientais. Isso é importante porque contribui para que os(as) docentes tenham como subsidiarem seus discursos, de forma que seus futuros posicionamentos não sejam falaciosos ou ainda meras repetições. Associado a isso, é possível notar que o contato com propostas de natureza temática leva os(as) licenciandos(as) a incorporarem, ainda que parcialmente, em algum momento de suas aulas, discussões menos deterministas, pautadas exclusivamente no conhecimento científico.

Os resultados também apontam que há ausência de algumas questões abordadas ao longo dos cursos de graduação. Dentre essas, por exemplo, as apontadas por Gehlen et al. (2014), relacionadas (i) ao estabelecimento de vínculos entre os temas e a realidade com a qual os(as) alunos(as) se encontram, problematizando-a; e, (ii) à abordagem dos conceitos científicos como meios ou instrumentos para compreender os temas e a realidade. Segundo essas autoras, os(as) licenciandos(as) evidenciaram uma postura diferenciada, mais crítica e próxima dos pressupostos da Abordagem Temática, ao refletir sobre essas questões. Apesar disso, as autoras reconhecem a dificuldade de romper com a lógica da abordagem conceitual e a necessidade de aprofundar discussões em torno do sujeito do conhecimento e da dinâmica de problematização.

Além disso, ressaltamos que uma ou duas disciplinas ao longo de todo um curso de formação inicial, muitas vezes desarticulada do trabalho de outras disciplinas, não é suficiente para promover modificações significativas na forma como o futuro professor irá organizar e executar suas aulas. Fatores como, por exemplo, as exigências colocadas pela coordenação pedagógica de uma determinada escola e/ou por um currículo oficial, parecem ser mais determinantes para os professores decidirem trabalhar com temas em suas aulas de Física.

Diante disso, para além do trabalho na formação inicial, compreende-se como fundamental a construção de estratégias para aprofundar a discussão acerca da abordagem de temas na formação docente continuada, entre elas: (i) a ampliação da articulação universidade-escola, com propostas formativas organicamente vinculas à escola; (ii) a construção de grupos de 
trabalhos nas escolas, para estudo e planejamento, focando na importância da apreensão da realidade para a seleção do conteúdo programático e para o estabelecimento de um diálogo problematizador entre docente e aluno; e (iii) a problematização das práticas já implementadas pelos docentes, para que experiências positivas e negativas, pautadas em temáticas, possam ser compartilhadas, valorizadas e, se necessário, replanejadas.

Por fim, com essas reflexões, esperamos ter contribuído para a construção de uma perspectiva mais abrangente em relação aos espaços e estratégias, desafios e potencialidades para a discussão de pressupostos da Abordagem Temática em cursos de formação inicial de professores e professoras.

\section{Agradecimentos}

Esse trabalho foi financiado pelo Conselho Nacional de Desenvolvimento Científico e Tecnológico (CNPq), Chamada Pública Universal MCTI/CNPq no 14/2013.

\section{Referências}

BARDIN, L. Análise de conteúdo. Lisboa: Edições 70, 1991.

BRASIL. Resolução CNE/CP 1, de 18 de fevereiro de 2002. Institui diretrizes curriculares nacionais para a formação de professores da educação básica, em nível superior, curso de licenciatura, de graduação plena. Brasília: CNE, 2002. Disponível em: http://portal.mec.gov. br/cne/arquivos/pdf/rcp01_02.pdf. Acesso em: 22 fev. 2019.

DELIZOICOV, D.; ANGOTTI, J.A.; PERNAMBUCO, M. C. A. Ensino de ciências: fundamentos e métodos. São Paulo: Cortez, 2007.

FEISTEL, R. A. B.; GEHLEN, S. T.; STRIEDER, R. B.; CARAMELLO, G. W. Abordagem temática e ensino de física: dificuldades e contribuições. In: ENCONTRO DE PESQUISA EM ENSINO DE FÍSICA, 13., 2011, Foz do Iguaçu. Atas [...]. Foz do Iguaçu: SBF, 2011.

FREIRE, P. Pedagogia do oprimido. 42. ed. rev. e atual. Rio de Janeito: Paz e Terra, 2005.

GEHLEN, S. T.; STRIEDER, R. B.; WATANABE-CARAMELLO, G.; FEISTEL, R. A. B.; HALMENSCHLAGER, K. R. A inserção da abordagem temática em cursos de licenciatura em física em instituições de ensino superior. Investigações em Ensino de Ciências, Porto Alegre, v. 19, n. 1, p. 217-238, 2014. Disponível em: https://www.if.ufrgs.br/cref/ojs/index. php/ienci/article/view/104/75. Acesso em: 22 fev. 2019.

HALMENSCHLAGER, K. R.; DELIZOICOV, D. Abordagem temática no ensino de ciências: caracterização de propostas destinadas ao ensino médio. Alexandria: revista de educação em ciência e tecnologia, Florianópolis, v. 10, n. 2, p. 305-330, 2017. DOI: https:// doi.org/10.5007/1982-5153.2017v10n2p305.

HUNSCHE, S. Professor “fazedor” de currículos: desafios no estágio curricular supervisionado em ensino de física. 2010. Dissertação (Mestrado em Educação) Universidade Federal de Santa Maria, Santa Maria, 2010. 
Silva, L. F.; Tavares, S. S.; Watanabe, G.; Halmenschlager, K. R.; Strieder, R. B.; Hunsche, S.

HUNSCHE, S.; AULER, D. O professor no processo de construção de currículos: desafios no estágio curricular supervisionado em ensino de física. Revista Electrónica de Enseñanza de las Ciencias, Vigo, v. 11, n. 1, p. 1-20, 2012. Disponível em: http:/ / reec. uvigo.es/volumenes/volumen11/REEC_11_1_1_ex566.pdf. Acesso em: 22 fev. 2019.

HUNSCHE, S.; AULER, D. O enfoque temático no ensino de física: desafios enfrentados por estagiários. In: SIMPÓSIO NACIONAL DE ENSINO DE FÍSICA, 18., 2009, Vitória. Atas [...]. Vitória: SBF, 2009.

RODRÍGUEZ-MARÍN, F; GARCÍA, J. E. El activismo que no cesa: obstáculos para incorporar la metodología didáctica basada en la investigación del alumno a la práctica de la educación ambiental. Revista Investigación en la Escuela, Sevilla, v. 67, p. 23-36, 2009. Disponível em: https://idus.us.es/xmlui/handle/11441/60787. Acesso em: 22 fev. 2019.

SILVA, A. G. A busca do tema gerador na práxis da educação popular. Curitiba: Editora Gráfica Popular, 2007.

SILVA, L. F.; CARVALHO, L. M. Professores de física em formação inicial: o ensino de física, a abordagem CTS e os temas controversos. Investigações em Ensino de Ciências, Porto Alegre, v. 14, n. 1, p. 135-148, 2009. Disponível em: https://www.if.ufrgs.br/cref/ojs/ index.php/ienci/article/view/414. Acesso em: 22 fev. 2019.

SILVA, L. F.; CARVALHO, L. M. A temática ambiental e as diferentes compreensões dos professores de física em formação inicial. Ciência \& Educação, Bauru, v. 18, n. 2, p. 369383, 2012. DOI: https://doi.org/10.1590/S1516-73132012000200009.

STRIEDER, R. B.; HUNSCHE, S.; WATANABE-CARAMELLO, G. Abordagem CTS no ensino médio: dificuldades encontradas por futuros professores de física. In: SEMINÁRIO IBERO-AMERICANO CIÊNCIA-TECNOLOGIA-SOCIEDADE NO ENSINO DAS CIÊNCIAS, 2., 2010, Brasília. Atas [...]. Brasília: UnB, 2010.

STRIEDER, R. B.; KAWAMURA, M. R. Educação CTS: parâmetros e propósitos brasileiros. Alexandria: revista de educação em ciência e tecnologia, Florianópolis, v. 10, n. 1, p. 27-56, maio 2017.

STRIEDER, R. B.; WATANABE-CARAMELLO, G.; GEHLEN, S. T. Abordagem de temas no ensino médio: compreensões de professores de física. In: ENCONTRO DE PESQUISA EM ENSINO DE FÍSICA, 12., 2010, Águas de Lindóia. Atas [...]. Águas de Lindóia: SBF, 2010.

STRIEDER, R. B.; WATANABE-CARAMELLO, G.; GEHLEN, S. T. Abordagem de temas no ensino médio: compreensões de professores de física. Ensaio: pesquisa em educação em ciências, Belo Horizonte, v. 14, n. 2, p. 153-169, 2012.

SUND, P. Discerning selective traditions in science education: a qualitative study of teachers' responses to what is importante in science teaching. Cultural Studies of Science Education, Dordrecht, v. 11, n. 2, p. 387-409, 2016. 
WATANABE, G.; KAWAMURA, M. R. Abordagem temática e conhecimento escolar científico complexo: organizações temática e conceitual para a proposição de percursos abertos. Investigações em Ensino de Ciências, Porto Alegre, v. 22, n. 3, p. 145-161, 2017. WATANABE, G.; RODRÍGUEZ-MARÍN, F. Aspectos da complexidade nas questões socioambientais: as abordagens no Brasil e na Espanha. Ciência \& Educação, Bauru, v. 24, n. 3, p. 543-562, 2018. DOI: https://doi.org/10.1590/1516-731320180030002.

WATANABE-CARAMELLO, G.; STRIEDER, R. B.; GEHLEN, S. T. Abordagem temática na formação de professores de física. In: SIMPÓSIO NACIONAL DE ENSINO DE FÍSICA, 19., 2011, Manaus. Atas [...]. Manaus: SBF, 2011.

WATANABE-CARAMELLO, G.; STRIEDER, R. B.; GEHLEN, S. T. Desafios e possibilidades para a abordagem de temas em aulas de física. Revista Brasileira de Pesquisa em Educação em Ciências, Belo Horizonte, v. 12, n. 1, p. 205-222, 2012. 
